\title{
Processo de construção de normas na escola e formação para a cidadania
}

\author{
Maria Augusta Salin Gonçalves \\ Orene Maria Piovesan
}

\section{Resumo}

Reflete sobre pesquisa-ação realizada em escola de ensino fundamental, com a finalidade de minimizar conflitos na escola, focalizando principalmente o processo de construção de normas, etapa final, que envolveu alunos, pais, professores, direção e funcionários da escola, e discute os resultados referentes às reuniões realizadas anteriormente com os professores. O material - gravação das reuniões, diário de campo e relato de observações - foi analisado com procedimentos interpretativos. Como resultado significativo, aponta a abertura de espaço para o diálogo, possibilitando que todos os segmentos da escola participassem do processo de construção de normas e garantindo liberdade a todos para assumir posicionamentos e defender idéias.

Palavras-chave: diálogo; formação da cidadania; construção de normas.

\begin{abstract}
The process of constructing rules at school and citizenship education

This paper discusses the results of an action-research experience, performed at an elementary school, aiming at the reduction of conflicts in the school. The main focus of the paper was the process of building and defining of the school rules, which involved students, parents, teachers, staff and the school administration. We also discuss results of the meetings held exclusively with the teachers before the beginning of this process. The research material records of meetings with the teachers, interviews, and field diary was analyzed using interpretative procedures. The most significant result of the process of building of rules is that it creates a space for dialogue among the different segments of the school, assuring to all the liberty to have an opinion and advocate their own ideas.
\end{abstract}

Keywords: dialogue; citizenship education; construction of rules. 


\section{Introdução}

A violência crescente que constatamos em todas as instâncias da vida atual é uma preocupação constante de todos nós. O cotidiano da escola também é permeado por momentos em que afloram graves conflitos de interação social. Trocas de palavras ásperas e agressões físicas entre os alunos são comportamentos que se manifestam com grande freqüência no ambiente escolar.

$\mathrm{Na}$ maioria das vezes, o que observamos é uma grande perplexidade por parte do professor, que fica sem saber como agir para minimizar a violência na escola e auxiliar o seu aluno na construção de interação social que se embase no diálogo, no respeito ao outro, na cooperação e na responsabilidade. As formas que ele geralmente utiliza buscando atingir esse objetivo são recomendações, castigos e ameaças de notas baixas. Diferentes estudos e a nossa própria observação nos apontam para a quase total inutilidade desses procedimentos. Exortações, ameaças e castigos, de maneira geral, não produzem mudanças duradouras nem contribuem para a solução dos conflitos que surgem no dia-a-dia da escola.

Com a intenção de buscar alternativas para minimizar a violência que ocorria com freqüência no cotidiano de uma escola de ensino fundamental (Escola AB) situada em bairro periférico, com inúmeros problemas sociais, como drogas, agressões, furtos e brigas constantes, realizamos, com as professoras dessa escola, uma pesquisa-ação que lhes proporcionasse momentos de reflexão e discussão sobre questões referentes a problemas de interação social, visando auxiliá-las a resolver os conflitos de forma construtiva. Em vista disso, realizamos, durante o ano de 1999 e o primeiro semestre de 2000, com as professoras das quartas e quintas séries da escola, reuniões periódicas, para discutir, a partir das situações de conflito que surgiam no cotidiano da escola, questões referentes a normas sociais, conflitos morais e cidadania. As reuniões foram realizadas com a participação de 14 professoras, fechando um total de 14 reuniões de, aproximadamente, 90 minutos.

Nesse período, realizamos com as professoras:

a) Discussões em torno de questões relativas ao desenvolvimento moral, oportunizando às professoras reflexão sobre a própria prática e relacionando-a com fundamentos teóricos da formação da consciência moral com base em Piaget (1994), Kohlberg (1984), Gilligan (1994), Puig (1999), Paulo Freire (1993, 1997), Cullen (1996) e Habermas (1989), entre outros.

b) Ações educativas, que, focalizando a busca de interação social construtiva, pretendem favorecer a emergência de autoconhecimento, reconhecimento do outro, solidariedade, cooperação e capacidade de diálogo.

No decorrer das reuniões, as professoras identificaram como uma possibilidade de minimizar a violência na escola a construção conjunta de normas que favorecessem a convivência no ambiente escolar. As reuniões com as professoras tiveram também a finalidade de prepará-las para o desenvolvimento do processo coletivo de construção de normas para a escola.

Nosso objetivo, neste artigo, é apresentar reflexões focalizando principalmente esse período final da pesquisa-ação realizada na escola $\mathrm{AB}$, quando ela assumiu a coordenação do processo de construção de normas, realizando reuniões que envolveram os alunos, pais, professores, a direção e os funcionários da escola. Com a intenção de possibilitar um maior entendimento dessa etapa, no que diz respeito à necessidade sentida pelos professores de realizar esse processo, discutimos também, neste artigo, alguns resultados referentes às reuniões realizadas anteriormente, designadas, no seu conjunto, como período de preparação.

Inicialmente, apresentamos algumas reflexões em torno da questão das normas. A seguir, analisamos o processo de construção de normas realizado nessa escola, bem como o resultado e a avaliação feita pelos participantes. Finalizando, tecemos algumas reflexões em torno do espaço escolar como lugar de formação para a cidadania.

\section{Normas e regras}

Normas e regras estão presentes em todas as interações sociais. No contexto da escola, existem normas e regras, implícitas ou claramente explícitas, que orientam 
ações individuais e coletivas dos participantes desse grupo social e definem expectativas de comportamento.

Neste texto, usamos a expressão regras quando nos referimos a prescrições que envolvem ações de selecionar meios para atingir fins determinados, indicando a forma mais racional para atingi-los. As regras se justificam pela sua eficácia em atingir os objetivos propostos, possuindo em seu cerne uma racionalidade técnica. Utilizaremos a palavra normas quando as diretrizes de ação envolvem formas de agir que dizem respeito à interação entre pessoas, sendo que da sua observância resulta a possibilidade de convivência com base no entendimento mútuo. A justificação de normas se dá no âmbito de princípios e valores. Nesse sentido, normas constituem a linguagem moral (Habermas, 1989).

Nesta pesquisa, o processo de construção de normas para a escola deveria definir formas orientadoras da ação de professoras, direção, alunos e pais, no contexto da escola, visando à emergência de interação social construtiva que minimize a violência presente no contexto escolar. $\mathrm{O}$ processo de construção de normas desenvolvido na Escola $\mathrm{AB}$ constituiu-se de sessões de discussão, realizadas com a participação dos diferentes segmentos da escola, com vista a atingir um consenso quanto a diretrizes de ação. As normas deveriam ser construídas e reconstruídas com base na argumentação, tendo como meta o consenso, buscando conciliar interesses individuais com interesses coletivos. Ao mesmo tempo, esse processo tinha a finalidade de possibilitar que os alunos compreendessem o que são normas sociais, para que servem, como são construídas e como podem ser modificadas.

Pertence à essência das normas, de maneira geral, que a sua não-observância envolva sanções. No âmbito da escola, entretanto, esta questão está estreitamente vinculada a objetivos educativos, sendo que a função da escola não é punir, mas possibilitar ao aluno uma formação que lhe capacite resolver de forma construtiva os conflitos, considerando direitos e deveres e visualizando-os em função do grupo social. A questão da sanção na escola não pode ser vista desvinculada desse processo. Nesse sentido, "colocar limites" faz parte dos objetivos de ações educativas que visam contribuir para a formação da cidadania, na medida em que promovem o exercício da autonomia nas decisões tomadas na perspectiva da responsabilidade social.

\section{O processo de construção de normas}

Pensamos que o processo de construção de normas com a participação dialógica de todos os segmentos da escola deva ser um processo permanente que se instala no espaço da escola e passa a fazer parte do seu cotidiano. Ele nunca está definitivamente concluído, pois está inserido em um contexto histórico, envolvendo relações de poder e de interação entre subjetividades, em permanente tensão. Essas relações são permeadas por uma trama de valores, expectativas, aspirações, frustrações, em seu estreito entrelaçamento com sentimentos de raiva, de proteção, de solidariedade, de prazer e de impotência.

Toda escola tem normas, ainda que possam não estar claramente explícitas. $\mathrm{O}$ processo de diálogo desencadeado na Escola $\mathrm{AB}$ pretendia trazê-las à luz, possibilitando a sua compreensão e reconstrução, segundo valores assumidos em consenso pela comunidade escolar.

A seguir, analisamos as duas etapas dessa pesquisa.

\section{Preparação do professor}

Como já dito, o objetivo deste artigo é focalizar principalmente a etapa final da pesquisa-ação, ou seja, o processo de construção de normas desencadeado na escola. Entretanto, para um melhor entendimento desse processo, discutiremos antes alguns pontos a respeito do período de preparação do professor, que caracterizam a necessidade sentida por eles da construção de normas.

Para fins de análise desse período, as 14 reuniões realizadas com as professoras foram gravadas, transcritas e analisadas com procedimentos de cunho hermenêutico.

Mediante a análise, constatamos que as professoras seguidamente se manifestaram no sentido da necessidade de colocar limites aos alunos. Essa questão foi tratada sempre com muita angústia pelas professoras, como expressam as palavras de uma delas, em uma reunião: 
- Será que com essas crianças que são problemas sérios a gente não está reproduzindo exatamente a mesma coisa que eles têm aí fora na vila? No que a gente está ajudando essas crianças? A gente vê o que acontece: muitos alunos que saíram daqui assaltam, roubam, fazem isso, fazem aquilo... aí vão lá, passam uma semana e aí são soltos de novo. Será que com esses alunos, aqui dentro da escola, a gente não está reproduzindo a mesma coisa? [...] Eles não têm nada que modifique o seu comportamento, que faça eles pararem para pensar que não estão no caminho certo (C. 31/05/2000).

Outra diz, referindo-se à forma dos limites: "Nós não queremos uma coisa rígida, não é um quartel, é só ajudar essa criança.” (E. 31/5/2000). Essa idéia é reforçada por uma professora com as palavras: "Eu concordo que está faltando limites para essas crianças... mas que tipo de limites? Aí, nós entramos em conflitos..." (R. 31/5/2000). Uma professora expressa, com muita emoção, um sentimento de impotência diante dos inúmeros problemas de seus alunos: "A gente vê todo esse contexto e se pergunta 'O que tu estás fazendo para essas crianças?' É isso que está me angustiando, será que estamos devolvendo eles para a sociedade como eles chegaram aqui, ou até piores?” (M. 31/ $5 / 2000)$.

A necessidade de colocar limites aos alunos, vivenciada pelas professoras e claramente manifestada nas suas falas, foi uma das razões que deram origem ao processo de construção de normas. As professoras, na maioria das vezes, diziam não saber como agir. Em momentos de conflito, era uma prática comum na escola mandar o aluno falar com a direção. Essa situação, entretanto, não era aceita sem questionamentos pelas professoras. Nesse sentido, uma professora diz: "Levar para a direção, todo o mundo está vendo que não está resolvendo nada. Temos que ter autoridade dentro das salas de aula.” (A. 31/5/ 2000).

Através da análise desses diálogos ocorridos nas reuniões durante o período de preparação, pudemos perceber nas professoras uma tensão entre o desejo de autonomia para resolver as questões conflituosas que surgem em sala de aula e a possibilidade de esses conflitos serem resolvidos em nível de direção da escola.
Essa tensão parecia fazer com que algumas professoras se sentissem imobilizadas em tomar decisões de forma autônoma, deslocando para as normas, que seriam coletivamente construídas, a função de uma autoridade externa que apontasse as soluções para os problemas. Nessa tensão pareciam mesclarem-se sentimentos de impotência e medo pela violência que ocorre no cotidiano da escola com sentimentos de culpa por as professoras sentirem-se responsáveis pela inclusão dos alunos-problema. Em alguns momentos, pareciam ver as normas como algo que poderia minorar esses sentimentos, na medida em que lhes indicariam "formas certas" de agir, proporcionando-lhes segurança e, em certa medida, uniformidade nas decisões tomadas.

Nesse sentido, orientamos o nosso diálogo para a questão da autonomia do professor para atuar em situações concretas de sala de aula, possibilitando ao aluno a participação crítica e o sentido da responsabilidade social, tendo em vista o desenvolvimento de um projeto educativo que vise à criação de uma nova racionalidade, que possibilite uma sociedade mais justa e mais humana.

Cabe aqui ressaltar que, além da discussão referente a normas, regras e "limites", as reuniões também buscaram possibilitar às professoras a articulação de conceitos teórico-práticos com as situações concretas da sala de aula, visando à ampliação de seus conhecimentos a respeito de questões referentes à prática educativa em geral e, em especial, ao desenvolvimento moral, às características da adolescência, à participação dialógica e aos processos culturais.

A análise das reuniões com as professoras nos permitiu constatar alguns avanços na forma de essas visualizarem os conflitos na escola: no reconhecimento de que a forma de ver o mundo dos alunos é diferente da sua e da importância de o professor conhecer os valores culturais da comunidade; na compreensão de que as crianças das classes populares têm uma baixa auto-estima e que necessitam sentir-se valorizadas e respeitadas; no entendimento de que normas sociais na escola devem ser construídas e reconstruídas dialogicamente, com a participação dos alunos, professores, direção, funcionários e pais; no reconhecimento de que as conseqüências da não-observância de normas na escola não devem ter caráter punitivo, 
mas estar, sobretudo, vinculadas a princípios educativos.

\section{Processo coletivo de construção de normas}

Para a análise desta etapa, as reuniões realizadas pelos diferentes segmentos da escola, em junho de 2000, foram gravadas e, posteriormente, transcritas. Da mesma forma, transcrevemos as entrevistas realizadas com participantes do processo de construção de normas. Esse material, incluindo também diário de campo e relato de observações, foi analisado com procedimentos interpretativos, permitindo realizar uma avaliação do processo e tecer algumas reflexões a respeito de questões referentes à participação dialógica e à construção da cidadania na escola.

Durante o processo de construção de normas, nas reuniões realizadas por todos os segmentos da escola, parece ter havido predominantemente uma preocupação em definir regras e normas e as conseqüências da sua não-observância. Entretanto, de maneira geral, questões mais fundamentais não foram abordadas. Não foram discutidos, nesta etapa do processo, que valores estariam na base dessas normas e qual o seu sentido em relação ao contexto cultural, nem as suas repercussões na solução dos problemas de violência através de ações educativas. Não obstante, houve algumas tentativas de aprofundar a discussão em torno de valores, como percebemos na manifestação de uma componente do grupo de professoras:

- Não é só a construção da cerca, mas é a construção de alguma coisa em que a gente acredita. Se é um valor que vai nortear a conservação da escola, por exemplo, eu penso que tem que ser um valor que tem a ver com aquilo que vale para a minha vida como pessoa. Tem que ser um valor que abranja uma coisa mais ampla, mas que tenha uma norma definida. Por que uma regra não funciona? Quando não é um valor para todo esse grupo (J. 31/5/ 2000).

Essas questões, no entanto, não foram aprofundadas, ficando os conteúdos dos diálogos, nesse momento, mais em nível de narração dos conflitos vivenciados pelas professoras na escola. Esses momentos, entretanto, também são importantes para consolidar a troca e o apoio mútuo, abrindo caminho para o encontro de soluções, ainda que provisórias.

Nas reuniões das professoras com os pais, a ação das professoras em geral limitou-se a anotar as falas dos pais e comunicá-las ao grande grupo. O apelo para que seja aumentada a segurança na escola apareceu com bastante força nas discussões dos grupos de pais. Da mesma forma, o castigo de tirar as coisas que dão prazer à criança. As professoras tomaram algumas posições neste sentido, condenando o castigo físico e a denúncia de $\mathrm{Co}$ legas, que foram sugeridos por alguns pais como medidas a serem incentivadas. Em relação aos pais, pelas suas manifestações, pudemos constatar que consideraram importante a sua participação na vida da escola.

Nas reuniões com os alunos, esses se manifestaram respondendo também sobre "o que mais os incomodava na escola". Apareceram como conflitos mais graves as agressões físicas e a colocação de apelidos. Nessa questão, nos parece necessário que se investigue qual o sentido que o apelido tem para os alunos e como isto se relaciona com as normas e valores que veiculam em seu contexto cultural.

\section{Definição das normas e regras}

Após as discussões realizadas pelas professoras, pais, alunos e funcionários, as professoras e a direção reuniram-se e elaboraram um documento contendo as normas que deveriam orientar as interações na escola. Analisando esse documento, pudemos realizar algumas reflexões, que apresentamos a seguir.

O documento abrange doze itens, que contêm prescrições de comportamentos de diferentes níveis, não expressos de forma hierárquica. Muitos deles se assemelham mais a regras que a normas. Na maioria deles, aparecem mais claramente definidas as conseqüências da não-observância das normas do que a expressão dessas em seu sentido positivo.

Uma das decisões tomadas nas reuniões foi a construção de um muro, pois pessoas estranhas transitavam pelo pátio, e os alunos, por sua vez, saíam do pátio para a rua, o que trazia muita insegurança 
às professoras, perturbando o trabalho pedagógico. Como essa foi uma exigência também dos pais, que afirmaram se sentir mais seguros em relação aos filhos, a direção aceitou a idéia. Anteriormente, ela era relutante a esse respeito, pois a construção de um muro parecia não corresponder à idéia de uma escola integrada na comunidade. A argumentação das professoras e dos pais mostrou a necessidade do muro para a solução de alguns problemas práticos, como possibilitar que alunos e professoras se sentissem mais seguros e, com isso, pudessem trabalhar melhor.

Pudemos perceber, no decorrer das reuniões realizadas no período de preparação, que havia na escola uma divergência entre o que era visualizado pela direção como ideal de inter-relação entre a escola e a comunidade - uma escola sem muros - e a realidade vivenciada pelos professores em seu cotidiano. Isso nos levou a discutir, nessas reuniões, as contradições que surgem, no dia-a-dia da escola, entre ideais educativos, expressos em teorias educativas, e as exigências impostas pela realidade concreta. Como conciliar a idéia de uma "escola sem muros", aberta à comunidade, com os sentimentos de medo e insegurança vivenciados pelas professoras e pelos alunos? $\mathrm{Na}$ discussão, foi possível chegar a um consenso, mudando-se o foco da reflexão para as questões: "Será que a não-existência de muros garante uma inter-relação positiva entre a comunidade e a escola? Será que a abertura da escola não se concretiza em outras formas que incluem uma participação mais efetiva da comunidade nas ações e decisões da escola?" Nas reuniões realizadas com a equipe de pesquisa no período de preparação, a discussão envolvendo essas questões trouxe avanços para a compreensão das relações entre a escola e a comunidade.

Voltando à análise do documento com as normas da escola, observamos que ele possui quatro itens referentes a comportamentos que devem ser evitados na sala de aula, no recreio, na saída da escola e nos passeios. Um outro item refere-se à proibição de agressão física e moral, definindo essa como "chutar, cuspir, dar tapas, socos, brigar, enforcar e outras atitudes que venham a machucar, palavrões, gestos ou expressões que magoam, calúnias". Um dos itens encerra uma proibição de porte de "armas, canivetes, fundas, ou objetos que coloquem em risco a segurança de todos. Esses serão recolhidos e etiquetados, registrados em caderno específico e tomadas as providências cabíveis, conforme ofício enviado pelo Conselho Tutelar". Dois itens referem-se ao cuidado com o material alheio: o patrimônio da escola e o material escolar dos colegas. Os outros itens abrangem ações a serem realizadas pela escola, tais como realizar "reuniões com os pais, trimestralmente, para conversar sobre o planejamento da escola"; em caso da nãoobservância das normas, enviar "bilhetes solicitando a presença dos pais na escola", etc. No documento, fica também estabelecido que "em situações-problema deve-se utilizar sempre o diálogo e, se esse não resolver, procurar ajuda com o adulto mais próximo".

A análise do documento nos mostra que esse tornou explícitas regras e normas construídas nas reuniões, não aprofundando a questão dos valores que as suportam. No entanto, o processo de diálogo realizado pela escola, envolvendo professoras, direção, pais, alunos e funcionários, não obstante as dificuldades e carências constatadas, constituiu-se momentos significativos que apontam para as possibilidades de formação para a cidadania na escola. Referindo-se ao processo, uma professora diz: "Foi uma grande lição de democracia, de participação para eles, os alunos." (R. 21/8/2000).

\section{Avaliação do processo}

Após a elaboração das normas, realizamos entrevistas com a direção, as professoras, os alunos, funcionários e pais, nas quais solicitamos que manifestassem a sua opinião sobre o processo.

As reuniões que antecederam o processo de construção de normas, com a equipe de pesquisa, realizadas no período de preparação, foram avaliadas pelas professoras como muito positivas, no sentido de possibilitar o apoio mútuo entre elas e, ao mesmo tempo, de sacudi-las da "acomodação". Uma professora expressou bem esses sentimentos:

- Quando começaram as reunióes, a gente teve condições de sentar, parar para pensar e falar das preocupações; porque quando eu cheguei aqui pensei 'Será que só acontece comigo?' Conversando com 
as outras professoras, que já estão aqui há oito ou dez anos, vi que todas tinham os mesmos problemas. As crianças já estavam viciadas naquele tipo de comportamento, e as professoras, acomodadas, aceitando aquela situação [...] Quando vem uma pessoa de fora ajudar, propondo para a gente alguma coisa ou alguma solução, a gente se sente bem, sabe que não está sozinha nesta luta. (P. 21/8/2000).

Outra diz: "A pesquisa serviu para a reflexão e também para a prática do dia-a-dia..." (M. 27/9/2000).

Pensamos que esses momentos revelam o sentimento de solidariedade entre as professoras, que foi se desenvolvendo ao longo do período das reuniões. Entendemos aqui solidariedade como a base afetiva da participação engajada, que se funda em sentimentos de identificação com padrões de interpretação de mundo, interesses, objetivos, crenças e valores compartilhados por membros de um grupo social, em que cada um se preocupa com o bem do próximo, porque esse é fundamental para a integridade do próprio grupo. A solidariedade é condição essencial para a construção de projetos coletivos que visem à solução de problemas comunitários. Como expressa Habermas (1991, p. 198), "a solidariedade tem a sua raiz na experiência de que cada um tem de fazerse responsável pelo outro, porque todos devem estar igualmente interessados na integridade do contexto vital comum do qual são membros”.

Quase todas as professoras avaliaram o processo em sua etapa final da construção das normas também como muito positivo, como expressa uma delas:

- Foi muito positivo, porque não partiu só da direção, foi um anseio que a gente viu que estava agitando a todos. Não só as professoras estavam descontentes, porque não estavam conseguindo fazer um bom trabalho, mas muitos alunos estavam sofrendo na mão dos que não têm limites (P. 21/8/2000).

\section{Outra professora diz:}

-Eu achei legal, porque antes os guris traziam arminhas na escola... agora que a gente fez as regras, eles não trazem mais... aí melhorou bastante na sala de aula, no pátio, na hora do recreio. Os guris jogavam pedrinhas nas gurias, agora não jogam mais (S. 21/8/2000).

As professoras manifestaram sentir-se mais seguras com a definição das normas: "Conseguiram dar uma segurança para aquele professor poder trabalhar em sala de aula... se sentir autoridade ali, porque antes não se sentia e chamava, muitas vezes, a direção na sala.” (J. 24/4/2001).

Constatamos também que o fato de as professoras se sentirem mais seguras em relação à disciplina em sala de aula fez com que procurassem formas mais interessantes de realizar ações educativas. Isso aparece na fala de uma professora, que diz:

- Até para montar as aulas a gente está mais animada, podemos fazer coisas diferentes. Antes, a gente ficava escravizada no quadro; a única maneira de dar aulas era no quadro: copiar, copiar, copiar, porque a partir do momento em que a professora parava de escrever no quadro para falar com eles, parecia que a aula tinha acabado, cada um fazia o que queria... ficavam dispersos (R. 21/8/2000).

Esse fato nos leva a refletir sobre a relação da disciplina com a ação pedagógica do professor. $\mathrm{Na}$ realidade, são processos interdependentes: na medida em que as ações desenvolvidas pelo professor não conseguem incentivar o interesse do aluno, esse tende a realizar atividades que perturbam o andamento da aula. Por outro lado, o tumulto que se propaga muitas vezes em sala de aula, em que aparece a falta de limites dos alunos que não têm controle sobre as próprias ações, gera um sentimento de impotência da parte do professor ante as situações de conflito. Com isso, o professor fica imobilizado e cai em uma rotina no que se refere a ações educativas, o que, por sua vez, aumenta a ocorrência de atos “indisciplinados”. Esse fato aponta para a importância de que a formação do professor o capacite a lidar com os inúmeros conflitos que surgem na realidade concreta das escolas e, ao mesmo tempo, lhe possibilite o conhecimento de ações educativas adequadas, que envolvam o aluno em um processo de construção conjunta.

Alguns alunos entrevistados se manifestaram, considerando também o processo de construção de normas como positivo, como diz um aluno da quinta 
série: "A professora consegue dar aula, mais do que antes. Tinha gente que não fazia nada e agora eles fazem.” (E. 27/9/2000). Outros afirmaram que algumas mudanças puderam ser observadas, outras não: “Quanto aos apelidos, mais ou menos. No recreio, agora está mais tranqüilo, não está tendo muita briga, igual a antes; diminuiu, só acontecem de vez em quando.” (R. 27/9/ 2000). Outro diz: "Achei legal, pararam de trazer coisas, ninguém mais trouxe funda nem facas; quanto aos apelidos, ainda não mudou. As brigas diminuíram; antes tinha bastante...” (J. 27/9/2000).

Pelas suas manifestações, de maneira geral, temos razões para supor que os alunos apreenderam o significado de normas mais no sentido de resolver problemas pragmáticos, que dizem respeito à aquisição de benefícios ou à defesa de ameaças, relativas a indivíduos ou grupos, do que no sentido de afirmações legais que visam à defesa de interesses coletivos. O processo de argumentação na formação do consenso não atingiu o nível convencional, segundo a classificação de Kohlberg (1984), mas parece ter permanecido em nível ainda egocêntrico, pré-convencional, em que as idéias são justificadas pelas conseqüências que possam advir de decisões e ações. A superação desse nível para o nível convencional é possibilitada quando o indivíduo se torna capaz de justificar as normas em função de regras e leis sociais vigentes na comunidade, que atuam como determinações externas. Não obstante, esse processo de diálogo abriu caminho para possibilitar a compreensão de normas sociais em níveis mais elevados. A meta educativa de um processo de diálogo que supera o nível convencional consiste em possibilitar a abertura para justificativas de normas embasadas em valores éticos que tenham em seu cerne o reconhecimento do outro, caracterizando um nível de argumentação pós-convencional.

A importância do diálogo parece também ter sido reconhecida por funcionários da escola, trazendo mudanças nas suas atitudes em relação à forma de lidar com os alunos. Um deles, o vigilante, manifestou-se no sentido de ter constatado mudanças positivas e de procurar conversar com os alunos quando surgem brigas:

-Notei diferença. Eles começaram a aprender a ter limites, porque o limite de um tem que ir até onde não invade o espaço do outro. [...] Tem muita criança que inclusive vem falar com a gente: "Tio, aquela criança lá está me incomodando.” Aí, eu digo: "Vamos lá, vamos sentar e conversar...” Então a gente resolve, e evita uma coisa mais séria (J. 21/8/2000).

Uma das mães manifestou, em entrevista, que considera que houve mudanças com o processo:

- Eu acho que deu uma melhorada, aos pouquinhos está melhorando (...) Eu estava preocupada com o muro, porque eu tinha medo de acontecer alguma coisa, roubar a criança, não só a minha, mas de qualquer outro. Agora já estão fazendo o muro, o ginásio... (N. 27/9/2000).

Nesta etapa, constatamos que houve uma maior ênfase nos resultados do processo - a definição de normas e regras e as conseqüências da não-observância dessas - do que no entendimento dialógico sobre a fundamentação dessas normas e sobre os meios de proporcionar aos alunos experiências de interação social construtiva. Não obstante esse fato, pois somente em raros momentos conseguimos identificar falas de entendimento mútuo e aprofundamento nas questões, a experiência realizada pela Escola AB trouxe avanços positivos. Como mais significativo apontamos a abertura do espaço para o diálogo entre professoras, direção, alunos, pais e funcionários, possibilitando que todos os segmentos da escola participassem do processo de construção de normas e garantindo liberdade a todos para assumir posicionamentos e defender idéias. Acreditamos nas possibilidades de o diálogo autêntico gerar transformações, pois, como diz Freire, é o "momento em que os humanos se encontram para refletir sobre a sua realidade tal como a fazem e desfazem". Como seres humanos, temos consciência das possibilidades e limites dos nossos conhecimentos e das nossas ações. É através do diálogo que, "refletindo juntos sobre o que sabemos e não sabemos, podemos, a seguir, atuar criticamente para transformar a realidade" (Freire, 1987, p. 125).

Consideramos, entretanto, o evento apenas como uma etapa no processo de construção de uma escola democrática, etapa que deve ser devidamente analisada e compreendida, para servir de base para ações e decisões a serem tomadas. 
Pensamos que avanços significativos realmente ocorrem quando a escola instaura como prática permanente a participação e o diálogo, possibilitando a revisão e reconstrução das normas e vinculando essas a ações educativas que permitam ao aluno experiências que favoreçam a compreensão e internalização dessas normas. Pensamos também que o processo de diálogo deve ter o caráter formativo de auxiliar o professor a caminhar em direção à autonomia, resolvendo conflitos segundo valores educativos que orientem as suas ações. Nesse caso, a definição das normas expressa a explicitação desses valores, favorecendo a discussão a respeito deles, a sua compreensão e inserção em práticas concretas. Quando o professor avançar nesse sentido, certamente as normas perderão o seu caráter coercitivo e exterior, que parecem ter adquirido neste momento do processo.

\section{Considerações finais}

A pesquisa-ação que realizamos na Escola AB, incluindo as etapas anteriores ao evento de construção das normas, se constituiu, sem dúvida, um espaço de formação do educador, possibilitando-lhe a aquisição de conhecimentos a respeito de saberes éticos e de ações educativas referentes ao desenvolvimento da consciência moral, possibilitando que ele se torne mais apto para lidar com os conflitos de interação social que surgem no cotidiano da escola. Pensamos que um trabalho conjunto como o que desenvolvemos nesta pesquisa-ação, em que o professor tem a possibilidade de refletir sobre a sua prática pedagógica e compreender, com o auxílio de teorias e práticas educativas, os conflitos que surgem no cotidiano da escola, pode contribuir para capacitá-lo melhor a auxiliar seus alunos a serem participativos e a buscarem coletivamente a solução de problemas através de diálogo. Queremos ressaltar, entretanto, que é importante ter clareza quanto ao desafio que se tem de enfrentar ao tentar transformar as relações de poder na escola, que, muitas vezes, sob a aparência de diálogo e participação, encobrem elementos de dominação. Essas condições, sem dúvida, dificultam o processo de abertura para a construção conjunta do novo que deve surgir do diálogo coletivo.

A escola não pode perder de vista o seu objetivo de incentivar o processo de participação de forma permanente, possibilitando, com freqüência, momentos de discussão, nos quais alunos, funcionários, pais e professoras possam ser realmente críticos, confrontem as suas idéias, reconstruam concepções e decisões e planejem ações coletivas, fazendo do espaço da escola um lugar de formação para a cidadania. Não há dúvidas de que esses momentos são sempre perpassados por conflitos, contradições e rupturas, mas também por vivências de entendimento mútuo e construção conjunta.

A capacidade de dialogicamente buscar soluções consensuais para conflitos, sem recorrer à coerção, se constitui o ponto de partida e de chegada de ações educativas que visem a essa formação. $\mathrm{O}$ espaço de participação que possibilita a emergência de um diálogo autêntico, superando as limitações geradas por relações de poder, traz em seu cerne os objetivos de uma educação que visa à emergência de uma nova racionalidade que possibilite a reconstrução da sociedade.

\section{Referências bibliográficas}

CULLEN, Carlos A. Autonomia moral, participación democrática y cuidado del otro. Buenos Aires: Ediciones Novedades Educativas, 1996.

FREIRE, Paulo. Medo e ousadia - o cotidiano do professor. Rio de Janeiro: Paz e Terra, 1987.

Pedagogia da autonomia: saberes necessários à prática educativa. São Paulo: Paz e Terra, 1997.

Pedagogia da esperança. Rio de Janeiro: Paz e Terra, 1993. 
GILLIGAN, Carol. La moral y la teoria: Psicologia del desarrollo femenino. México: Fondo de Cultura Económica, 1994.

HABERMAS, Jürgen. Consciência moral e agir comunicativo. Rio de Janeiro: Tempo Brasileiro, 1989.

. Justicia y solidaridad (Uma toma de posición en la discusión sobre a etapa 6 de la teoria de la evolución del juicio moral de Kohlberg). In: APEL, K.-O. et al. (Org.). Ética comunicativa y democracia. Barcelona: Editorial Crítica, 1991.

KOHLBERG, Lawrence. Essays on moral development: the psychology of moral development. São Francisco: Harper and Harper, 1984. v. 2.

PIAGET, Jean. O juízo moral na criança. São Paulo: Summus Ed., 1994.

Pedagogia da autonomia: saberes necessários à prática educativa. São Paulo: Paz e Terra, 1997.

PUIG, Josep M. Ética e valores: métodos para um ensino transversal. São Paulo: Casa do Psicólogo, 1999.

Maria Augusta Salin Gonçalves, doutora em Educação pela Universidade do Vale do Rio dos Sinos (Unisinos), é professora e pesquisadora do Programa de Pós-Graduação em Educação do Centro de Ciências Humanas dessa universidade.

guta.voy@terra.com.br; guta@unisinos.br

Orene Maria Piovesan (Fapergs) é graduanda em Pedagogia na Unisinos e bolsista de Iniciação Científica do Programa de Pós-Graduação em Educação do Centro de Ciências Humanas dessa universidade.

orene@terra.com.br

Recebido em 10 de março de 2006.

Aprovado em 15 de agosto de 2006. 